\title{
Role of dispersion conditions on grindability of yttria stabilized zirconia (YSZ) powders
}

\author{
S RAMANATHAN*, K P KRISHNA KUMAR ${ }^{\dagger}, P$ K DE and S BANERJEE \\ Materials Science Division, Bhabha Atomic Research Centre, Mumbai 400 085, India
}

MS received 15 May 2004; revised 12 January 2005

\begin{abstract}
A precursor for zirconia -8 mole\% yttria $\left(\mathrm{YSZ}_{-} \mathrm{ZrO}_{2}-8 \mathrm{~m} \% \mathrm{Y}_{2} \mathrm{O}_{3}\right)$ powder was prepared by coprecipitation and the calcination temperature was fixed as $900^{\circ} \mathrm{C}$ from TG-DTA and XRD studies. The calcined powder could be dry ground only to a mean particle size $\left(D_{50}\right)$ of $6 \mu \mathrm{m}$ containing substantial amount of coarse agglomerates in the size range 10-100 $\mu \mathrm{m}$. The dispersion conditions for its wet grinding were evaluated through zeta-potential and viscosity studies. The zeta-potential variation with $\mathrm{pH}$ of the aqueous suspensions of the powder exhibited maximum numerical values at 3 and $11 \mathrm{pH}$, exhibiting the ideal pHs for dispersion stability through electrostatic columbic repulsion mechanism. Slurries of dry ground powders with solid concentration in the range 15-30 vol.\% exhibited pseudo-plastic flow characteristics, indicating presence of flocculates. With progress of grinding, the increase in viscosity of the slurries became less significant with decreasing solid concentration. Even though the particle size of the ground slurries decreased with decreasing solid content, there was little change in it for slurries with solid content $<20$ vol. $\%$. Grinding conditions for formation of sinter-active powders of YSZ with sub-micron size $\left(D_{50} \sim 0.7 \mu \mathrm{m}\right.$ free of agglomerates of size $>5 \mu \mathrm{m}$ ) were established. Compacts from this powder could be sintered at $1400^{\circ} \mathrm{C}$ to translucent bodies with 99\% theoretical density.
\end{abstract}

Keywords. YSZ powder; dispersion behaviour; grindability.

\section{Introduction}

During the synthesis of oxide powders by solution based techniques (e.g. solution combustion, decomposition of metal nitrates, precipitation etc), agglomerates of fine crystallites of the precursors or oxides form and their size vary up to many microns. The calcination conditions for formation of the oxide from the precursor precipitates are generally fixed through detailed TG-DTA and XRD studies. Broad size distribution and presence of coarse agglomerates (size $>10 \mu \mathrm{m})$ in the calcined powder lead to formation of heterogeneity in green microstructure of the shapes formed by both wet casting and dry pressing techniques. Such heterogeneities introduce defects in the final sintered bodies leading to deleterious effects on their properties. Bodies could not be sintered to near theoretical density with no porosity. Grinding of these agglomerates into fine particles free of coarse ones (mean size of $\left.D_{50}<1 \mu \mathrm{m}\right)$ improves densification to near theoretical density at a relatively lower temperature and results in homogeneous microstructure. Thus a study of grinding behaviour of the oxide agglomerates formed during precipitation and calcination is an important aspect. The grindability of the powder is influenced by various para-

\footnotetext{
*Author for correspondence (srama@apsara.barc.ernet.in)

${ }^{\dagger}$ Summer Research Fellow of the Indian Academy of Sciences
}

meters, e.g. powder preparation conditions (reactant concentrations, washing and drying conditions), milling conditions (mill parameters) and dispersion conditions of the powder in suspending media (water content and its $\mathrm{pH})$. During dry grinding, with decrease in the agglomerate size, the powder forms a cake along the walls of the pot. Further reduction in the agglomerate size is possible only by wet grinding. Efficiency of wet grinding is influenced by the dispersion conditions used. Even though a large amount of literature is available for the synthesis of fine powders of advanced ceramic materials, no systematic study is reported about the role of dispersion conditions on the grinding behaviour of these agglomerates to fine powder and its sinterability.

The dispersion of oxide particles in water can be achieved by either the electrostatic columbic repulsion mechanism (due to presence of adsorbed charge on them) or by steric hindrance mechanism (due to the adsorption of a polymeric molecule on their surface) (Pierre 1991). During grinding it is essential to keep both the particles being ground and formed, dispersed so that further grinding remains efficient (i.e. flocculation is expected to hinder efficiency of grinding). Flocculation occurs due to the weak Van der Waal force of attraction in the absence of charge on the particles. An underestimated aspect of study in processing of agglomerates of ceramic oxide powder is the role of dispersion conditions on their grindability. Even though it has been emphasized for the slurry formu- 
lation for shape forming by slip casting and tape casting techniques (Fries and Rand 1996; Hellobrand 1996), not much study exists on the role of dispersion on the grinding behaviour of agglomerates of oxides formed by solution based techniques.

The role of dispersion conditions on the mixing and grinding of oxide powders in aqueous media is discussed recently (Houivet et al 2002). The quantitative parameters used for evaluating the degree of dispersion in aqueous oxide suspensions are zeta-potential and rheological behaviour (Hunter 1981; Jean and Wang 2000; Houivet et al 2002). The zeta-potential is a measure of the amount of charge present on the particle surface relative to the bulk of the aqueous media so that columbic repulsion between them stabilizes their dispersion. It is a function of the powder characteristics, presence of impure ions and $\mathrm{pH}$ of the medium. Even at the $\mathrm{pH}$ of maximum zeta-potential, with increasing solid concentration in suspension (i.e. in slurries of powders), flocculates are said to exist and is exhibited by shear thinning characteristics (i.e. the pseudo-plastic flow behaviour), which is attributed to the breaking away of flocculates upon shearing (Reed 1995; Vallar et al 1999). Lesser viscosity and lesser dependency of it with shear rate are characteristics of a good dispersion. For effective grinding, zeta potential of the slurry should be maximum and the solid concentration should be such that the shear experienced during grinding in the mill is high enough to break the flocculates.

Highly dense yttria stabilized zirconia (YSZ) bodies find application as electrolyte materials for solid oxide fuel cells (SOFC), oxygen sensor, pumps etc (Jaganathan et al 1980). These components are synthesized through standard ceramic processing techniques such as slip casting, extrusion, tape casting and dry pressing. The most versatile method for preparation of the powder required for the above processes is co-precipitation technique. The co-precipitated gel decomposes into crystalline oxide compound upon heating and the conditions are generally obtained through a detailed TG-DTA and XRD studies. As emphasized previously, elimination of the coarse agglomerates present in the calcined powders into sub-micron size by wet grinding is essential for making the abovementioned components with high density and homogeneous microstructure at a lower sintering temperature. There is no reported literature on the effect of dispersion conditions on the grindability of YSZ powder agglomerates formed by co-precipitation technique. Hence the above aspects were studied.

\section{Experimental}

The hydroxide gel of zirconium and yttrium (corresponding to $\mathrm{ZrO}_{2}-8 \mathrm{~m} \% \mathrm{Y}_{2} \mathrm{O}_{3}$ composition) was prepared by the standard reverse strike co-precipitation by drop-wise addition of a solution of zirconium oxy-chloride and yttrium nitrate $(0 \cdot 1 \mathrm{M}$ metal ion concentration) into a bath of excess ammonia $(0 \cdot 1 \mathrm{M})$ kept stirred vigorously. The jelly precipitate formed was filtered, washed repeatedly till no trace of chloride was found by silver nitrate test. The wet gel was oven dried at $70^{\circ} \mathrm{C}$. The oven dried gel was dry ground in a planetary mill (M/s Fritsch, Germany) to form into powder. This precursor powder was subjected to TG-DTA (M/s Netzsch) and XRD (M/s Philips) studies to fix the calcination temperature. The precursor was calcined at $900^{\circ} \mathrm{C}$ to form into the oxide compound (YSZ).

The precursor powder calcined at $900^{\circ} \mathrm{C}$ was dry ground planetarily for $1 \mathrm{~h}$. The particle size distribution of the powder agglomerates was obtained using laser light scattering technique (Master-sizer 2000 from M/s Malvern, UK). The zeta-potential variation of the aqueous suspensions of the powder with $\mathrm{pH}$ was obtained by laser Doppler velocimetry (Zetasizer 3000 from M/s Malvern, UK), while the variation of viscosity with shear rate for slurries of varied solid concentrations were obtained using a cone and plate viscometer $(\mathrm{M} / \mathrm{s}$ Boehlin, UK). Both the dry and wet grinding studies were carried out in the planetary mill under a standard set of conditions $(30 \mathrm{~g}$ of powder in $80 \mathrm{cc}$ alumina pot with 15 alumina balls of $10 \mathrm{~mm}$ diameter at a mill r.p.m. of 200). The extent of grinding was assessed through determination of their particle size distributions. Wet grinding was carried out up to $10 \mathrm{~h}$. The sinterability of the powders with varying sizes has been evaluated from the bulk density of the dry pressed (150 MPa) samples sintered at $1400^{\circ} \mathrm{C}$ for $2 \mathrm{~h}$ and the sintered specimen characterized for its microstructure.

\section{Results and discussion}

The TG-DTA pattern of the precursor is shown in figure 1. The oven dried precursor exhibited a total loss of weight

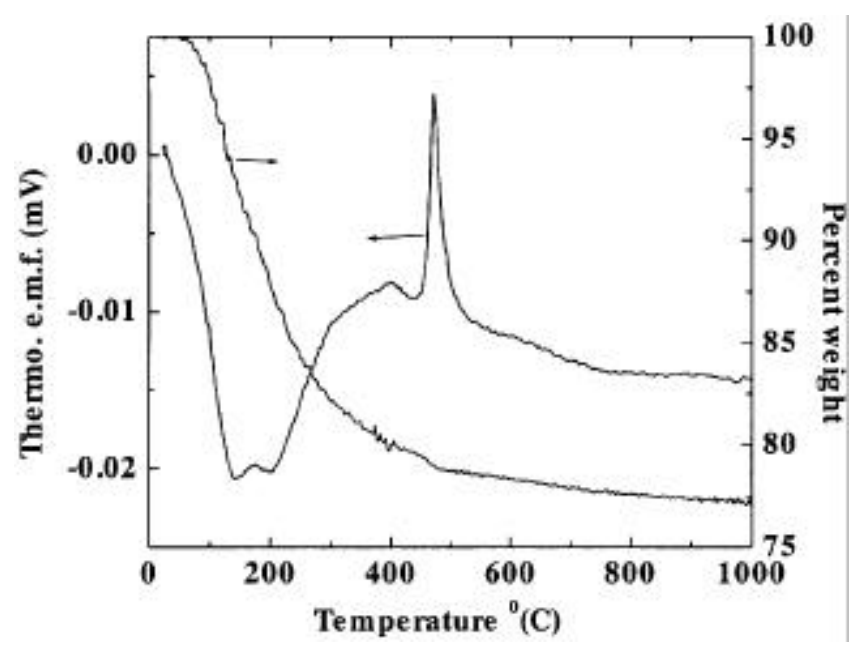

Figure 1. TG-DTA pattern for oven dried YSZ gel. 
of about $24 \%$ in stages (temperature ranges, 25-300 and $400-500^{\circ} \mathrm{C}$ ) accompanied by a broad endotherm and a sharp exotherm. The endotherm has been attributed to the loss of capillary water and water of adsorption while the exotherm is attributed to the crystallization of cubic YSZ phase (Ramanathan 1995). Even though the exotherm was complete below $500^{\circ} \mathrm{C}$, there was a minor amount of loss in weight up to $900^{\circ} \mathrm{C}$. Hence the gel was calcined at $900^{\circ} \mathrm{C}$ and was found to be cubic YSZ phase as shown by XRD (figure 2, pcpdf no. 30-1468). As the calcined powder upon dry grinding for $1 \mathrm{~h}$ formed a cake along the walls of the pot, dry grinding was stopped at this stage. The particle size distribution of the powder dry ground for $1 \mathrm{~h}$ and that subsequently wet ground are shown in figure 3. It is obvious that dry grinding yields powder

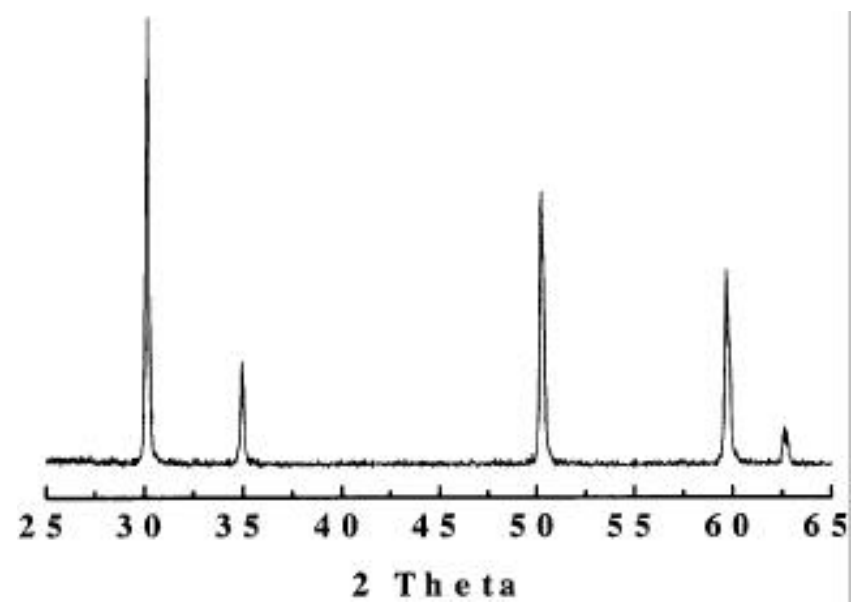

Figure 2. XRD pattern for $\mathrm{YSZ}$ gel calcined at $900^{\circ} \mathrm{C}$.

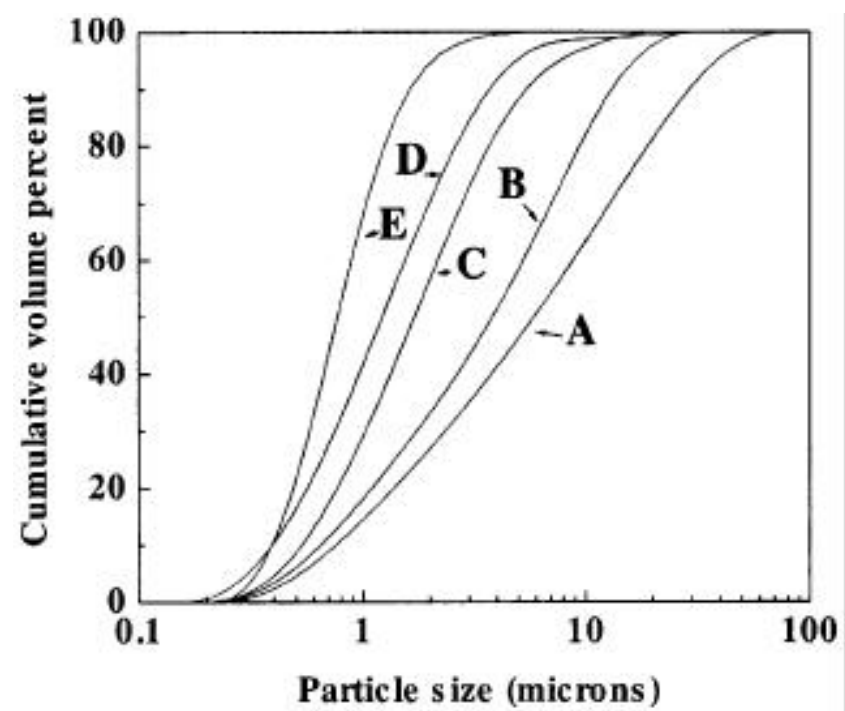

Figure 3. Particle size distribution of the dry and wet ground slurries (20 vol.\% solid content at a pH of 3$)$. A. powder dry ground for $1 \mathrm{~h}$; B, C, D, E. wet ground for 1, 2, 4, $10 \mathrm{~h}$, respectively. agglomerates with their mean size of about $6 \mu \mathrm{m}$ containing substantial amount of coarser particles (size $>10 \mu \mathrm{m}$ ) which need to be eliminated to improve their sinterability to near theoretical density. As dry grinding for $1 \mathrm{~h}$ resulted in formation of cake along the walls of the pot, the coarser agglomerates present at this stage can be eliminated only by wet grinding.

As discussed previously, efficient wet grinding needs well-dispersed slurries. As the degree of dispersion of the slurries is quantitatively measured through zeta-potential and rheological behaviour, these aspects were studied. The variation of zeta-potential with $\mathrm{pH}$ of the aqueous suspensions of the YSZ powder, as shown in figure 4, exhibited a maximum in the numerical value in the $\mathrm{pH}$ ranges 2-3 (positive value) and 10-11 (negative value). It is generally positive in acidic and negative in alkaline media. As the zeta-potential is characteristic of the surface composition of the material, the numerical value has been found to vary with preparation conditions (like precursor compound, calcination temperature) and the medium. There is a wide variation in the reported values of zeta-potential of the YSZ powders and is attributed to the method of preparation and trace amounts of impurities (Seabsugh et al; Basu et al 2001; Ramanathan et al 2004). The $\mathrm{pH}$ at which the net charge on the surface of the suspended particles become zero (i.e. point of zero charge) was again characteristic of the nature of the oxide compound and it was found to be at a $\mathrm{pH}$ of 6 for this powder. The numerical value of maximum zeta-potential was more in acidic medium than in alkaline medium (figure 4). Hence slurries of YSZ were formulated at a pH of 3.

The variation in viscosity plots for slurries with varying volume percent solid content of un-ground powder is shown in figure 5 . The viscosity of the slurry with 30

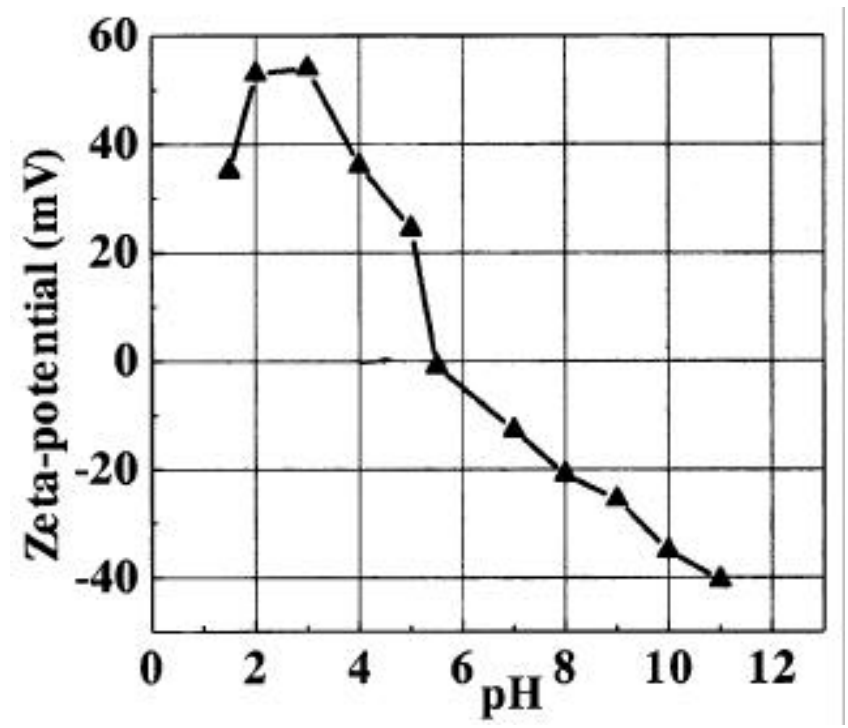

Figure 4. Zeta-potential variation with $\mathrm{pH}$ for aqueous suspensions of $900^{\circ} \mathrm{C}$ calcined YSZ powders. 
vol.\% solid at a $\mathrm{pH}$ of 6 was higher than that of the same slurry at a $\mathrm{pH}$ of 3 , bringing out the importance of zetapotential on the viscosity. At the point of zero charge (i.e. $\mathrm{pH}$ of 6), the particles in suspension does not possess any charge and hence they flocculate leading to higher viscosity. As the viscosity is lower at the $\mathrm{pH}$ of maximum zetapotential, slurries were formulated at this $\mathrm{pH}$. As the solid content decreased from 30-15 vol.\%, the slurry viscosity and its dependence with shear rate decreased. Further, the decrease becomes less significant with decreasing solid

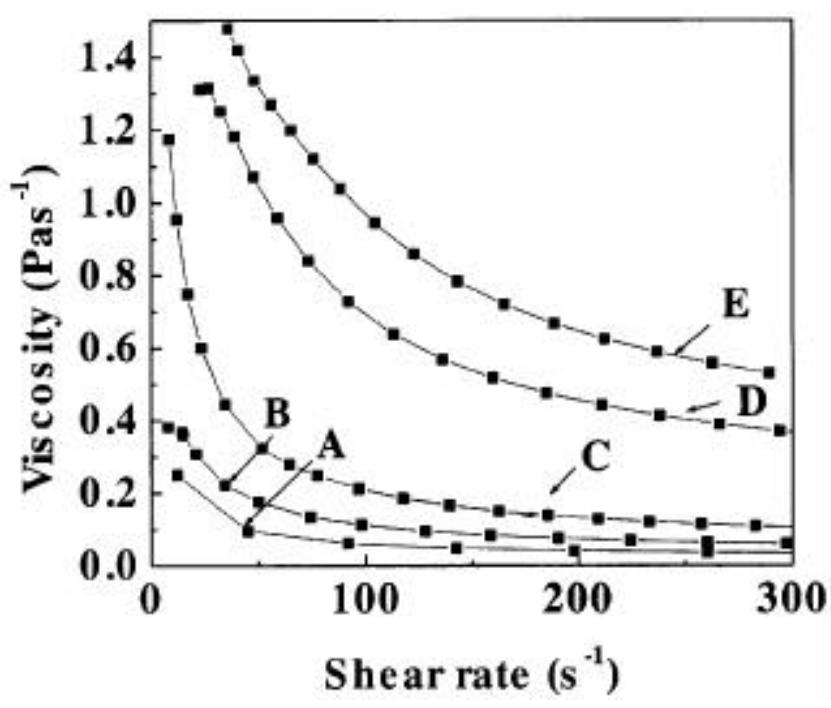

Figure 5. Variation of viscosity with shear rate plots for YSZ slurries (before grinding) A, B, C, D. slurries 15, 20, 25 and 30 vol. \% solid contents at a $\mathrm{pH}$ of 3 . E. slurry with 30 vol. \% solid content at a $\mathrm{pH}$ of 6 .

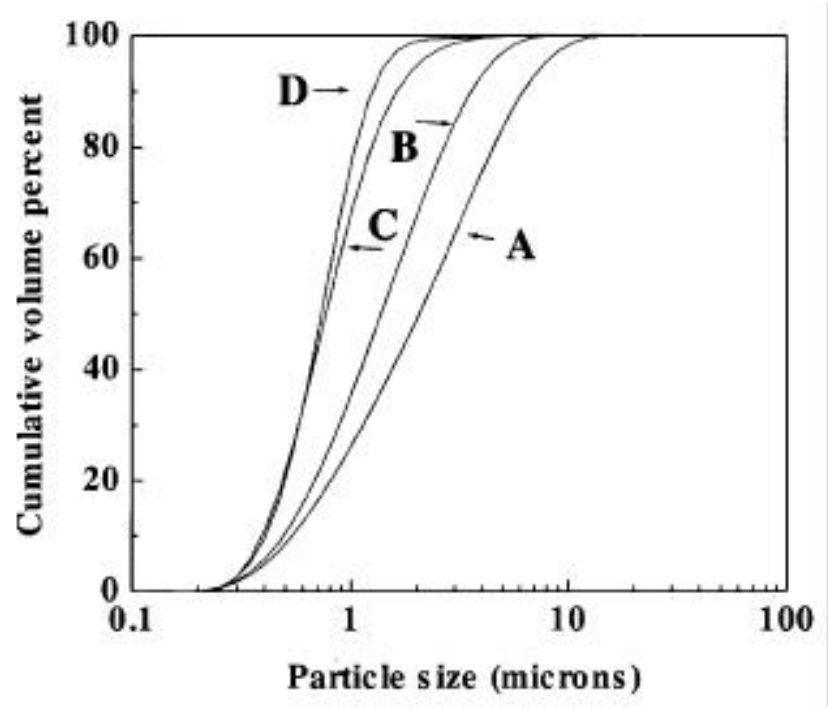

Figure 6. Particle size distribution of the wet ground slurries with varying solid contents. A, B, C, D. slurries with 30,25 , 20, 15 vol. $\%$ solid content. content in the slurry. The shear rate above which viscosity becomes independent of it also decreases with dilution.

The flocculates present in slurries entrap water inside their structure thereby making it not available for flow and hence increase the viscosity. Upon shearing, the flocculates break and the water becomes available for flow thereby decreasing the viscosity. Thus the decrease in the viscosity with increasing shear rate has been attributed to the breaking away of the flocculates present in the slurries. The shear rate above which viscosity becomes less dependent on it (i.e. closer to Newtonian behaviour), is a measure of the strength of the flocculates. A decrease in this value with decreasing solid concentration in slurries exhibits decrease in the flocculate strength. In the shear rate independent region of the viscosity plots these flocculates cease to exist. For a given set of conditions of grinding, the shear experienced by the slurries during grinding is expected to remain constant. With dilution of the slurry, the shear experienced by it during grinding becomes higher than the critical shear for absence of flocculates, leading to improvement in the efficiency of the process.

The progress of grinding with time for the slurry with $\mathrm{pH} 3$ and solid concentration of $20 \mathrm{vol} \%$ is shown in figure 3 . The time taken for grinding increases with decreasing particle size and formation of submicron size powder requires extensive grinding. Even though it takes only $2 \mathrm{~h}$ to reduce the mean size $\left(D_{50}\right)$ from 6 to $1.8 \mu \mathrm{m}$, further reduction of size to $0.7 \mu \mathrm{m}$ takes another $8 \mathrm{~h}$. The role of solid concentration on the grinding behaviour of slurries is studied and the size distribution plots are shown in figure 6. The efficiency of grinding increases with decreasing solid content in the slurry (i.e. results in a lesser particle size). However, the slurries with 15 and 20 vol.\% solid content were ground to the same submicron size $\left(D_{50} \sim 0.7 \mu \mathrm{m}\right)$, while those with higher vol.\% solid content could not be ground to the same degree of fineness. To understand this observation, a study on the evolution of viscosity with progress of grinding for various slurries was attempted.

The variation of viscosity before and after grinding for slurries with 20, 25 and 30 vol.\% solid content is shown in figure 7. Again the increase in viscosity of the slurry with progress of grinding became less pronounced with decreasing solid content (i.e. very little change in the slurry with solid content of $20 \mathrm{vol} . \%$ ). The evolution of viscosity with progress of grinding is attributed to formation of more particles, partial evaporation of the solvent and the change of $\mathrm{pH}$. The $\mathrm{pH}$ of YSZ slurries with varying solid content was found to remain essentially the same (2 to 3 ). The loss due to evaporation is expected to be same for all slurries as the pots were covered with the lids under identical conditions. Hence dilution (i.e. increasing water content) appears to make the contributions due to increased number of particles formed and evaporation less significant. As the viscosity of the slurry remained essentially the same for solid concentration of $20 \mathrm{vol} \%$ and below, 
the particle size distributions of them after grinding remained the same. Slurries with solid content more than 20 vol.\% exhibited higher ground size due to substantial increase in viscosity with progress of grinding. Thus the

Table 1. Solid content of slurries used for grinding (10 h), final particle size and sintered density of pellets from the powder.

\begin{tabular}{lcc}
\hline $\begin{array}{l}\text { Volume percent solid } \\
\text { content in slurry }\end{array}$ & Size $\left(D_{50}, \mu \mathrm{m}\right)$ & $\begin{array}{c}\text { Percent theoretical } \\
\text { density }\end{array}$ \\
\hline 30 & $2 \cdot 1$ & 87 \\
25 & $1 \cdot 4$ & 93 \\
20 & $0 \cdot 7$ & 99 \\
15 & 0.7 & 99 \\
\hline
\end{tabular}

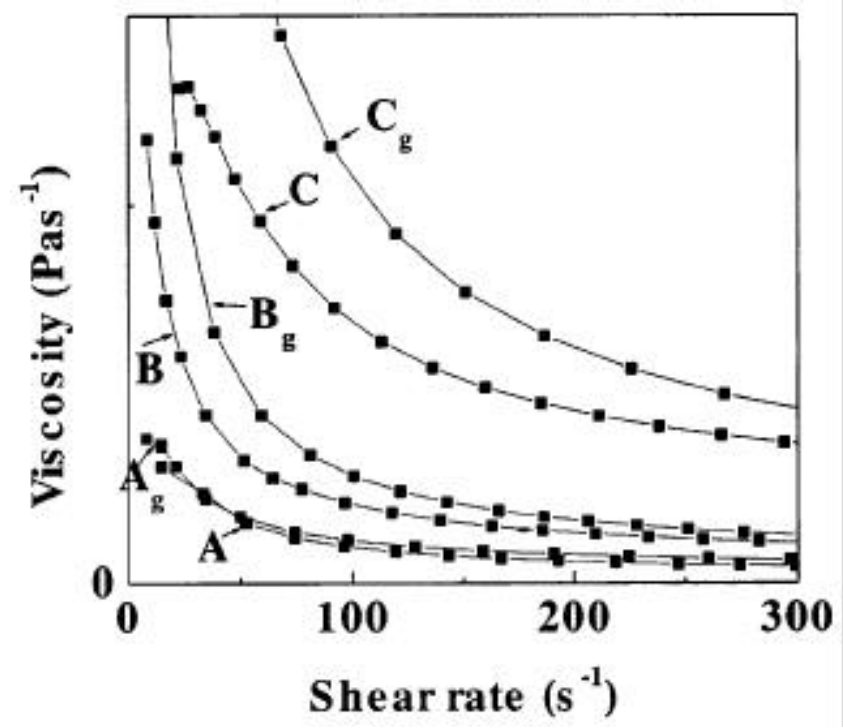

Figure 7. Variation of viscosity with shear rate for YSZ slurries with progress of grinding. A, B, C. slurries with 20, 25, 30 vol. $\%$ solid content before start of grinding; $A_{g}, B_{g}, C_{g}$. slurries with $20,25,30 \mathrm{vol} . \%$ solid content after grinding.

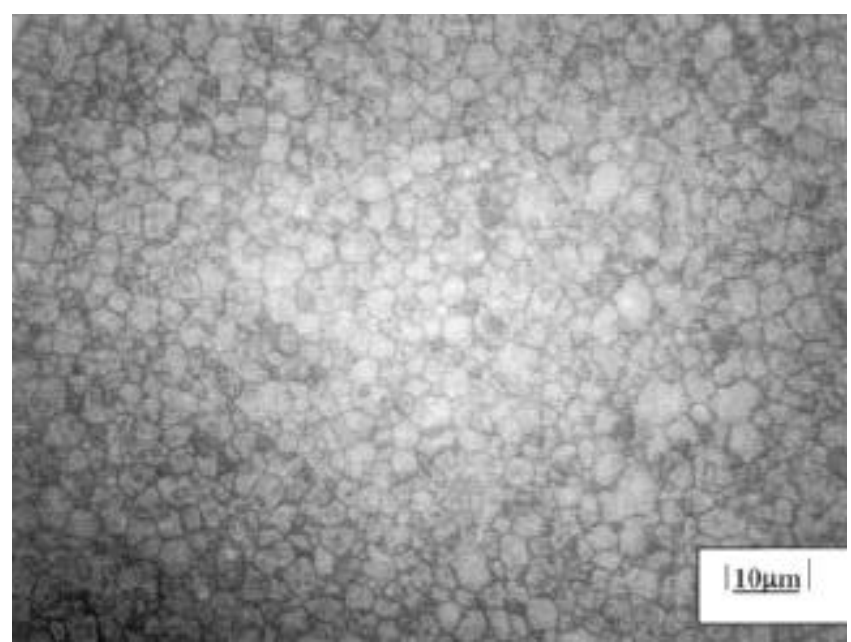

Figure 8. Typical microstructure of YSZ compact (99\% T.D.) sintered at $1400^{\circ} \mathrm{C}$. increase of viscosity of the slurry during grinding appears to hamper efficiency of grinding.

The sintered density data of the compacts (sintered at $1400^{\circ} \mathrm{C}$ for $2 \mathrm{~h}$ ) of powders with varying sizes (obtained by grinding with varying solid content) showed a drastic increase in the density with decreasing particle size (table 1). Translucent bodies having a density of $99 \%$ theoretical, nil open porosity and uniform grain structure (figure 8) with grain size ranging from 5 to $10 \mu \mathrm{m}$ could be obtained at $1400^{\circ} \mathrm{C}$ only by using the finest powder. The contamination from the grinding media (as assessed from the weight of the balls before and after grinding) was less than $0.2 \%$.

\section{Conclusions}

The oven dried YSZ co-precipitated gel crystallizes into the oxide compound below $900^{\circ} \mathrm{C}$. Dry grinding yielded powders with substantial amount of coarse agglomerates (with size $>10 \mu \mathrm{m}$ ) which exhibited poorer sinterability. Only wet grinding could eliminate these agglomerates. The results of a combined study of zeta-potential, viscosity (i.e. parameters indicative of degree of dispersion) and particle size data exhibited that the slurries with solid concentration $<20$ vol. $\%$ at a $\mathrm{pH}$ of 3 could be efficiently wet ground to form sub-micron size $\left(D_{50} \sim 0.7 \mu \mathrm{m}\right)$ powder. Bodies from this powder could be sintered at $1400^{\circ} \mathrm{C}$ to translucent bodies with near theoretical density.

\section{Acknowledgements}

The authors would like to thank Shri B B Kalekar, Analytical Chemistry Division and Shri B R Ambekar, Applied Chemistry Division, for their assistance in TG-DTA and XRD studies.

\section{References}

Basu Rajendra N, Randall Clive A and Mayo Marrilea J $2001 \mathrm{~J}$. Am. Ceram. Soc. 8433

Fries Robert and Rand Brian 1996 Materials science and technology, processing of ceramics-part I (eds) R W Cahn et al (Weinheim: VCH Publishers Inc). Vol. 17A p. 153

Hellobrand Hans 1996 Materials science and technology, processing of ceramics - part I (eds) R W Cahn et al (Weinheim: VCH Publishers Inc). Vol. 17A p. 189

Houivet D, Fallah J E and Haussonne J M $2002 \mathrm{~J}$. Am. Ceram. Soc. 85321

Hunter R J 1981 Zeta-potential in colloidal science - principle and applications (London: Academic Press)

Jaganathan K P, Tikku S K, Ray H S and Ghosh A 1980 Technological applications of solid electrolytes and their applications (ed) E C Subbarao (New York and London: Plenum Press) p. 201

Jean J H and Wang H R 2000 J. Am. Ceram. Soc. 83277

Pierre Alain C 1991 Ceram. Bull. 701281 
Ramanathan S, Muraleedharan R V, Roy S K and Nair P K K 1995 J. Am. Ceram. Soc. 78429

Ramanathan S, Krishnakumar K P, De P K and Banerjee S 2004 J. Mater. Sci. 393339

Reed J S 1995 Principles of ceramic processing (New York: Wiley)
Seabsugh M M, Swartz S L and Dawson W J A Report on tubular SOFC with deposited nanoscale YSZ electrolyte (www. nextechmaterials.com)

Vallar S, Houivet D, Fallah J E, Kervadec D and Haussome J M 1999 J. Eur. Ceram. Soc. 191017 